
and Aromatic Plants

An International Journal

ISSN: 2619-9645 | e-ISSN: 2667-5722

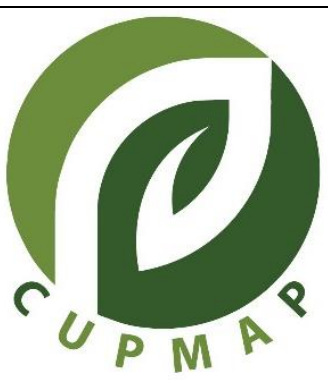

\title{
Natural Substances and Coronavirus: Review and Potential for the Inhibition of SARS-CoV-2
}

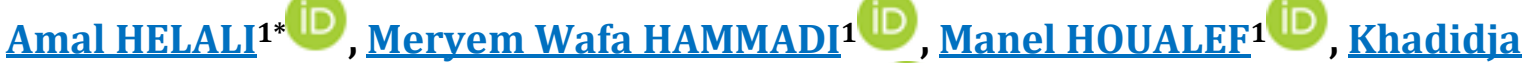 \\ BENCHACHOU 1
}

\begin{abstract}
${ }^{1}$ Department of Pharmacy, Faculty of Medecine, University ABOU BEKR BELKAID, 13000, Tlemcen, Algeria
*Corresponding author : amal.helali@univ-tlemcen.dz
\end{abstract}

\begin{abstract}
Coronaviruses are responsible for an increasing economic, social and mortality burden, as the causative agent of diseases such as the severe acute respiratory syndrome (SARS), the Middle East Respiratory Syndrome (MERS) and recently the COVID-19. Existing natural compounds, especially those known for their antiviral activity, may be useful as therapeutic agents against coronavirus infections. This study aims to review the currently available scientific literature on natural substances of plant origin with promising antiviral effects against coronaviruses. PubMed, Science Direct and Biomed Central databases were searched for articles including the keywords "Coronavirus", "SARS-CoV-2" as well as "Alkaloids", "Polyphenols", "Terpenes" and "Secondary metabolites". 145 research articles published between 2003 and 2020 were selected. The majority of the studies on natural substances acting against coronaviruses were performed in the last two years: 2020 (31,72\%) and 2021 (60,69\%) coinciding with the emergence of the new coronavirus SARS-CoV-2. Most studies were performed by in silico methods with a percentage of $66,67 \%, 25,45 \%$ by in vitro methods and only $7,88 \%$ by in vivo tests. Our research resulted in a list of 963 natural substances of plant origin tested against Coronavirus. Polyphenols represent the most tested secondary metabolites against Coronavirus, followed by terpenes and then alkaloids. Quercetin, Catechin, Glycyrrhizin, Kaempferol, Rutin, Curcumin, Myrecitin, Apigenin and Hesperidin were the most cited substances. In the future, we hope that the active ingredients of medicinal plants can be used to treat SARSCoV-2 infection in humans.
\end{abstract}

Key Words: SARS-CoV-2, COVID-19, Natural compounds, Secondary metabolites, Review.

(C) CUPMAP. All rights reserved.

\section{Introduction}

Coronaviruses were first identified in humans in the 1960s. They are viruses that cause emerging diseases, i.e., new infections due to changes or mutations in viruses. Human coronaviruses mainly cause respiratory infections, ranging from the common cold to severe and sometimes lethal pneumonia (Vabret, Dina, Brison, Brouard, \& Freymuth, 2009).
Three coronaviruses cause infections that can be severe or even fatal: severe acute respiratory syndrome (SARS-CoV) that appeared in China and caused the 2003 epidemic, Middle East Respiratory Syndrome (MERS) that caused the 2012 epidemic, and severe acute respiratory syndrome coronavirus-2 (SARS-CoV-2) that causes coronavirus-2019 (COVID-19) disease (Asrani, Hasan, Sohal, \& Hassan, 2020). 
In late December 2019, China reported the emergence of a new infectious disease, caused by a virus named severe acute respiratory syndrome coronavirus-2 (SARSCoV-2), initially transmitted from animals to humans and then from humans to humans. Within a short time, SARS-CoV-2 spread to other countries, killing thousands of people. As a result, the World Health Organization (WHO) has declared the Coronavirus-2019 (COVID-19) disease a pandemic and currently it is considered the second leading cause of death after cardiovascular disease. The WHO states that no effective therapy has been approved to date for the prevention or treatment of this disease. Although vaccines have now been launched, evidence of their safety and efficacy in the population is still awaited. This suggests the need to broaden the scope of research for effective treatments. Among other therapeutic options, natural products and derivatives constitute a vast source of potential drug molecules. Nature provides a huge well of active ingredients that remain to be discovered to treat diseases.

Historically, $80 \%$ of clinically important drug developments are still inspired by these nature-derived entities. Therefore, products of natural origin or phytochemicals have continuously served humanity as a noble source of therapeutically important elements. And these products are of considerable importance in the event of a global health crisis and represent one of the most practical and promising approaches to reduce the intensity of pandemics through their therapeutic potential.

The main objective of this study is to review the currently available scientific literature on natural substances of plant origin with promising antiviral effects against Coronavirus.

\section{Material and Methods}

\subsection{Bibliographic research of the data}

The databases used were: PubMed, Science Direct and Biomed Central. The bibliographic search and the downloading of articles were carried out during the period from January 1 , 2003 to May 31, 2021.

\subsection{Search strategy}

First, the keywords of the search equation were entered in the search engines of the databases used. We used English keywords related to the virus such as: "Coronavirus", "SARS-CoV-2", and related to phytotherapy and natural compounds sush as: "Alkaloids", "Polyphenols", "Terpenes" and "Secondary metabolites". Afterwards, we used the following filters: between 2000 and 2020, academic articles, in English. The articles we included in the research project met the following criteria:

- Any article design: in silico study, in vitro trial, ex vivo trial, in vivo trial, randomized controlled trials, clinical trials and meta-analyses with full text available in Open Access or downloadable;

- Articles written in English or French;

- Articles published during the period from January 1, 2003 to May 31, 2021.

\subsection{Data analysis and exploitation}

After downloading the considered articles, a deep reading was necessary to classify the articles and note the following informations:

- Year of publication;

- Country;

- Type of study;

- Substance's name;

- Substance's Chemical structure;

- Substance's plant origin;

- Plant's scientific name and botanical family;

- Substance's chemical class;

- Antiviral mechanism of action.

The data collected was then reported on Excel $\AA$ and Google Sheets $\AA$ softwares to convert the results into graphs and facilitate the analysis task. 


\section{Results and Discussion}

A total of 5330 articles were identified by electronic search on PubMed, Science Direct, and BioMed Central. A summary of the study selection process is shown in Figure 1. 1881 articles were selected based on title and abstract, and 1368 after duplicate removal. At this stage, full texts were assessed and 1220 articles were excluded for ineligibility. Finally, 145 studies were included in our study. The search yielded a list of 963 natural substances of plant origin tested against Coronaviruses.

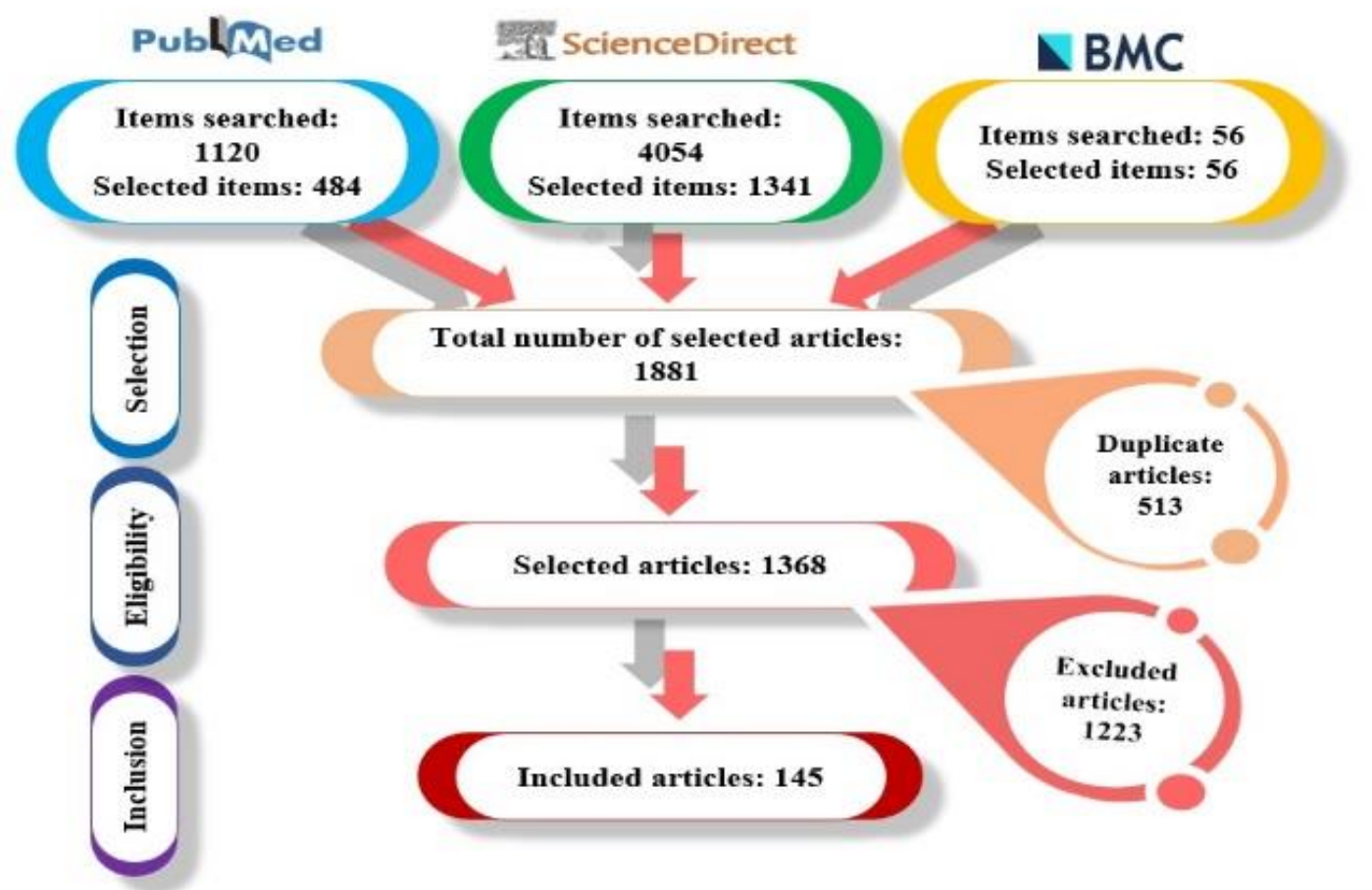

Figure 1. Articles search and selection's flowchart.

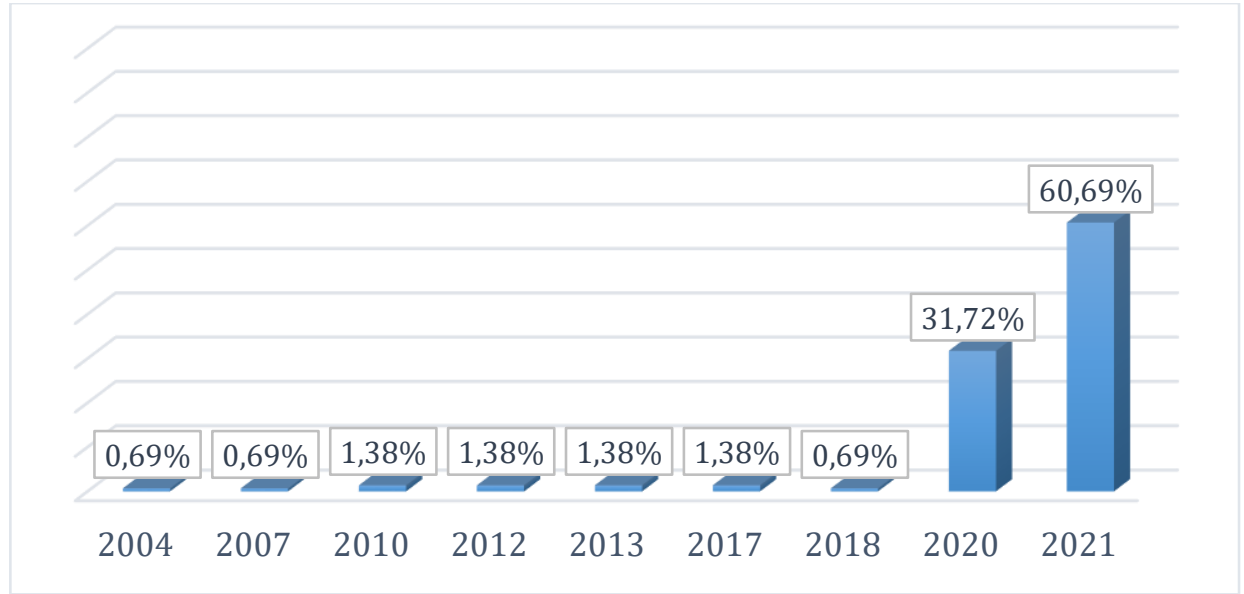

Figure 2. Articles distribution by publication's date.

\subsection{Year of publication}

The majority of the studies on natural substances acting against Coronaviruses were carried out in the last two years: 2020
(31.72\%) and 2021 (60.69\%), 2004 represents the year of the first publication and the number of articles published between 2004 and 2020 did not change significantly Figure 2. 
This finding can be clearly justified by the emergence of the new coronavirus SARSCoV-2 and the universal scope and severity of the pandemic caused by it compared to the last two epidemics due to SARS-CoV-1 and MERS-CoV.

\subsection{Country}

The states producing the most publications are the Asian countries mainly India with a percentage of $35.2 \%$ followed by China $(16.6 \%)$ then South Korea (9.7\%). The other countries: Egypt, Germany, Nigeria, USA, Brazil, Taiwan published between 6 and 3 articles and the rest including Algeria published less than 3 articles Figure 3.

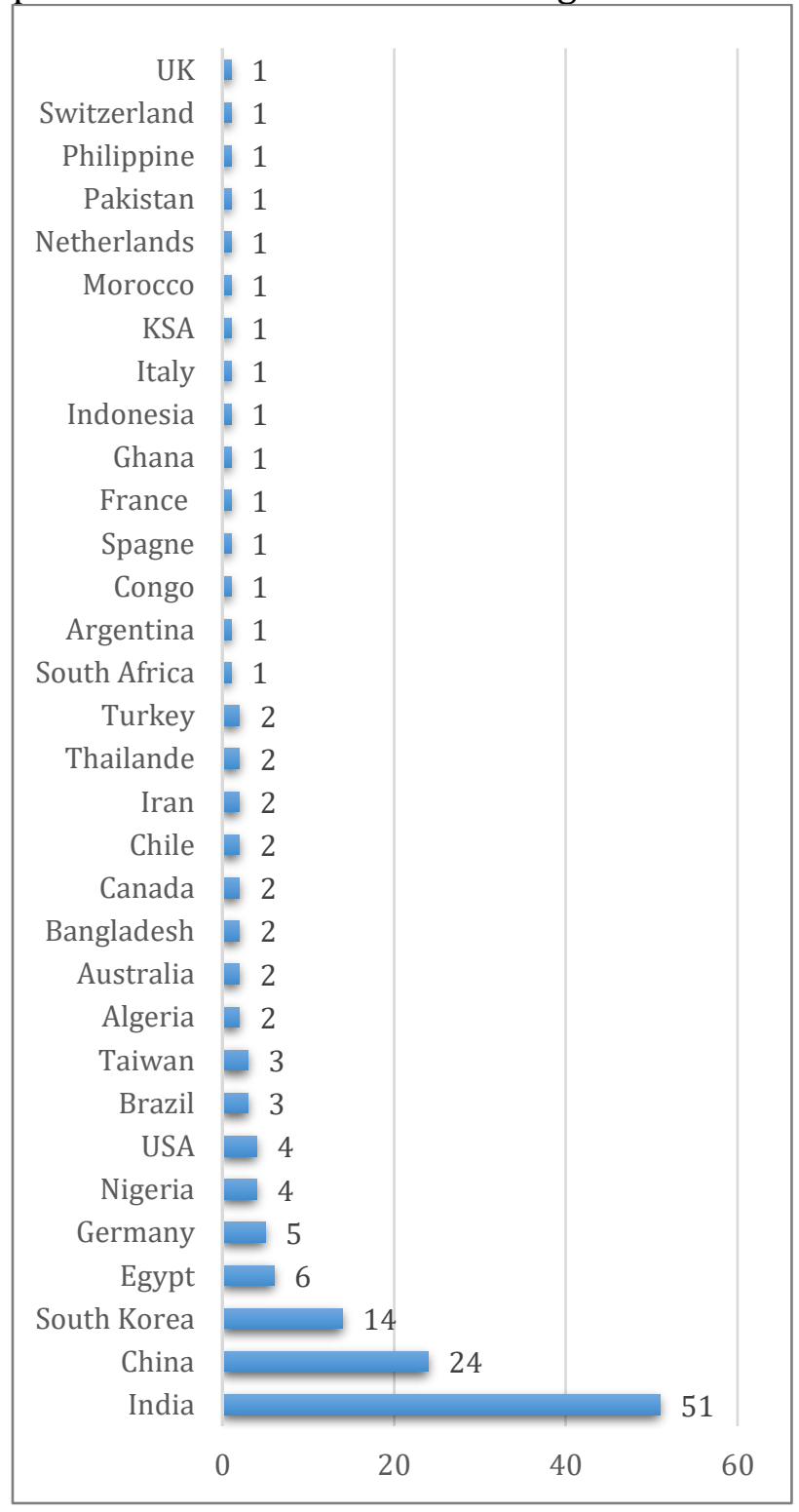

Figure 3. Articles distribution by country.

\subsection{Type of study}

Most of the studies on Coronaviruses and natural substances were carried out by the in silico method with a percentage of $66.67 \%$, $25.45 \%$ by in vitro methods and only $7.88 \%$ by in vivo tests Figure 4.

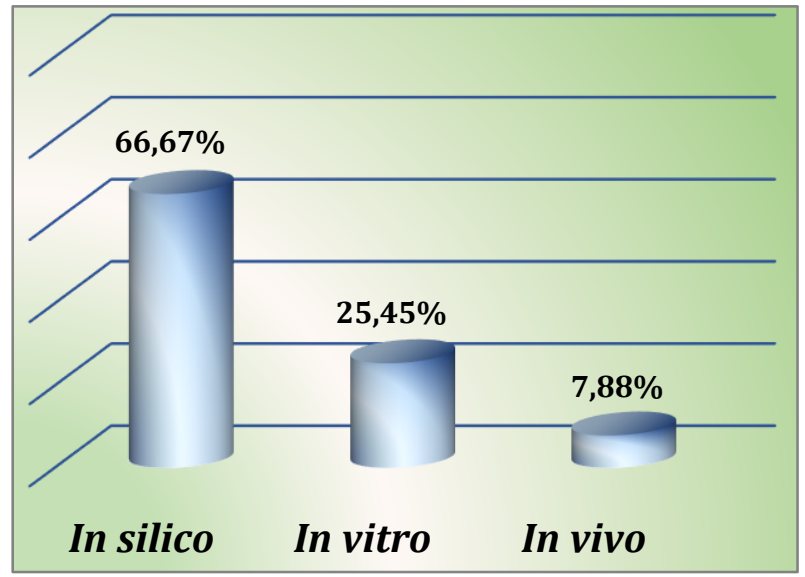

Figure 4. Articles distribution by study's type.

In silico methods are virtual screening approaches or methods based on algorithms developed for screening a large number of molecules in a shorter time and identifying a potential drug candidate (Hariprasad Puttaswamy et al., 2020). The use of these approaches has increased in the last two years, which is expected due to:

- The rapid result provided by these methods;

- The possibility of anticipation and prediction without the need for raw materials, extraction or purification;

- The ethical approach that does not require the use of animals;

- The lower costs and risks compared to traditional methods.

\subsection{Substance's chemical classes}

Of the 963 natural substances mentioned in the articles studied, polyphenols represent the most tested secondary metabolites against Coronavirus with a percentage of $51 \%$, followed by terpenes (29\%) and then alkaloids (18\%). The other compounds such 
as some primary metabolites constitute only $2 \%$ of the studied substances Figure 5.

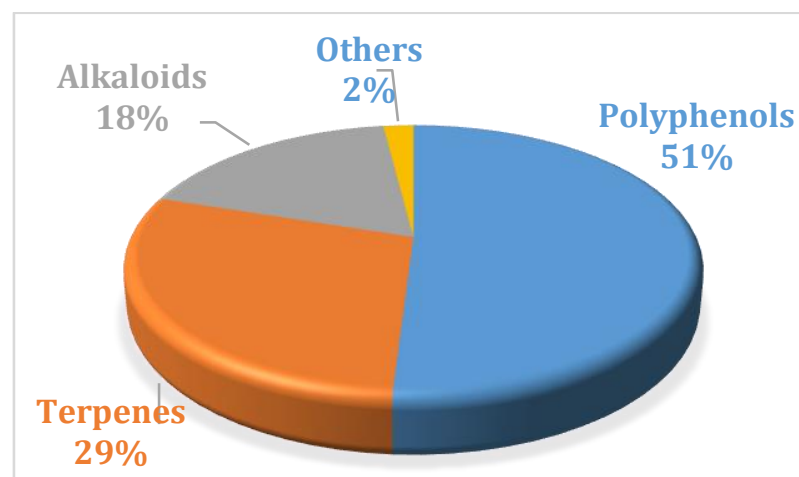

Figure 5. Molecules distribution by chemical classes.

Polyphenols are natural molecules known to have antiviral activity against a wide range of viruses, including HIV-1, HIV-2, HSV-1, HSV-2, influenza virus, dengue virus, HBV, $\mathrm{HCV}$, infectious bronchitis virus (IBV), Murbarg virus, Ebola virus, Newcastle disease virus (NDV), polio virus-1, lentivirus and coronavirus.

In the case of the latter, polyphenols act against coronaviruses using various mechanisms, including activation or inhibition of cell signaling pathways or arrest of the papain-like protease (PL pro) and the enzyme 3-chymotripsin-like protease (3CLpro)(Shin, Oh, \& Jeong, 2021).

\subsection{Botanical family}

Of the 963 natural substances mentioned in the articles studied, the Menispermaceae represents the most studied botanical family against Coronavirus with a percentage of $6.4 \%$ followed by the Asteraceae (6.3\%) then the Rosaceae (5.6\%) and Lamiaceae (5.3\%). The other botanical families present a percentage lower than 4.5\% Figure 6.

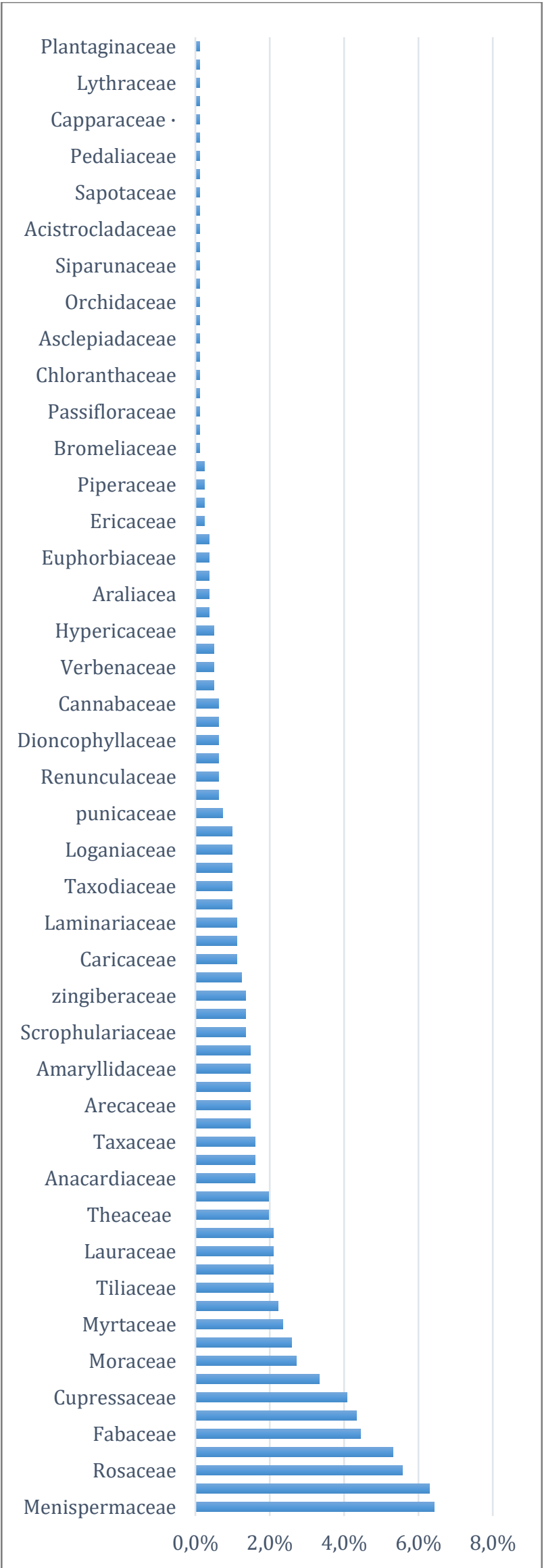

Figure 6. Molecules distribution by origin specie's botanical family. 
Table 1. The 10 most quoted natural substances.

Natural substance

\section{Catechin and analogs}

Camellia sinensis

Carica papaya

Mangifera indica

Moringa oleifera

Acacia nilotica

Psidium guajava

Rosa hybrida
Chemical class

Polyphenol

Virus
SARS-CoV
SARS-CoV-2

SARS-CoV-2

Action mechanism

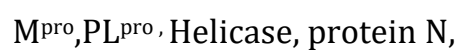

protein S, RBD, ACE2, RdRp,

CTSL, Nsp6, Nsp15 and furin

inhibitor.Proteine $\mathrm{S}$

interaction with GRP78 and

replication inhibitor

Reduce cytokine storm

Antioxidant agent
Study design

References

In silico

In vitro

In vivo

(Allam et al., 2020;

Arokiyaraj, Stalin, Kannan,

\& Shin, 2020; Attia et al.

2021; Du et al., 2021;

Elsbaey, Ibrahim, Bar, \&

Elgazar, 2021; R. Ghosh,

Chakraborty, Biswas, \&

Chowdhuri, 2020b; Gogoi

et al., 2021; Gupta et al.,

2020; Halder et al., 2021;

Hariyono, Patramurti,

Candrasari, \& Hariono,

2021; Jang et al., 2021;

Jang et al., 2020; Jena,

Kanungo, Nayak, Chainy, \&

Dandapat, 2021; Kumar et al., 2021; Liu,

Raghuvanshi, Ceylan, \&

Bolling, 2020; Meyer-

Almes, 2020; Mhatre, Naik, \& Patravale, 2021; Mishra et al., 2021; Natesh et al.,

2021; Nguyen et al., 2021; Pitsillou, Liang, Hung, \&

Karagiannis, 2021;

Pitsillou, Liang, Ververis,

Hung \& Karagiannis,

2021; Roh, 2012; Shin et

al., 2021; Singh, Sk,

Sonawane, Kar, \&

Sadhukhan, 2020; Umar et al., 2021; Vardhan \&

Sahoo, 2021; Yañez et al

2021; M. Zhao et al., 2021) 


\begin{tabular}{|c|c|c|c|c|c|}
\hline \multirow[t]{2}{*}{$\begin{array}{c}\text { Quercetin and analogs } \\
\text { Geranii Herba } \\
\text { Ephedra sp } \\
\text { Crocus sativus } \\
\text { Allium cepa } \\
\text { Broussonetia papyrifera } \\
\text { Moringa oleifera } \\
\text { Psidium guajava } \\
\text { Camellia sinensis } \\
\text { Rosa hybrida } \\
\text { Azadirachta indica } \\
\text { Mangifera indica } \\
\text { Ginkgo biloba } \\
\text { Corchorus olitorius } \\
\text { Justicia adhatoda } \\
\text { Psidium guyava } \\
\text { Lespedeza cuneata } \\
\text { Polygonum aviculare } \\
\text { Rhododendron aureum } \\
\text { Taxillus kaempferi }\end{array}$} & Polyphenol & $\begin{array}{c}\text { SARS-CoV } \\
\text { MERS-CoV } \\
\text { SARS-CoV-2 }\end{array}$ & $\begin{array}{l}\text { Inhibit SARS-CoV-2 cell entry } \\
\text { via ACE2 receptor } \\
\text { Inhibit proteolytic process, } \\
\text { 3CLpro, PLpro, RdRp and } \\
\text { interaction with HR2 domain } \\
\text { Decrease inflammation } \\
\text { factors } \\
\text { Reduces cytokine storm } \\
\text { Antioxidant agent }\end{array}$ & $\begin{array}{l}\text { In silico } \\
\text { In vitro } \\
\text { In vivo }\end{array}$ & $\begin{array}{l}\text { (Arokiyaraj et al., 2020; } \\
\text { Attia et al., 2021; Azim et } \\
\text { al., 2020; Du et al., 2021; } \\
\text { Gao, Song, \& Song, 2020; } \\
\text { Gheware et al., 2021; K. } \\
\text { Ghosh, Amin, Gayen, \& Jha, } \\
\text { 2021; Ibrahim et al., 2020; } \\
\text { Kumar Verma et al., 2021; } \\
\text { Kushwaha et al., 2021; Liu } \\
\text { et al., 2020; Mesli, Ghalem, } \\
\text { Daoud, \& Ghalem, 2021; } \\
\text { Meyer-Almes, 2020; } \\
\text { Nguyen et al., 2021; Niu et } \\
\text { al., 2021; Park et al., 2017; } \\
\text { H. Puttaswamy et al., } \\
\text { 2020; Shaji et al., 2021; P. } \\
\text { Sharma \& Shanavas, 2020; } \\
\text { Shin et al., 2021; Singh et } \\
\text { al., 2020; Umar et al., } \\
\text { 2021; Xiong et al., 2021; } \\
\text { Xu, Gao, Liang, \& Chen, } \\
\text { 2021; Yañez et al., 2021) }\end{array}$ \\
\hline & Terpene & $\begin{array}{c}\text { SARS-CoV } \\
\text { MERS-CoV } \\
\text { SARS-CoV-2 }\end{array}$ & $\begin{array}{c}\text { Inhibitor of the inflammatory } \\
\text { response / prevents the } \\
\text { development of a cytokine } \\
\text { storm } \\
\text { Inhibitor of 3CLpro, PLpro, } \\
\text { RdRp, TMPRSS2, protein S, } \\
\text { RBD, ACE2, Nsp1, furin and } \\
\text { Endoribonuclease }\end{array}$ & $\begin{array}{l}\text { In silico } \\
\text { In vitro } \\
\text { In vivo }\end{array}$ & $\begin{array}{l}\text { (F. Chen et al., 2004; L. } \\
\text { Chen et al., 2020; Ding et } \\
\text { al., 2020; Diniz, Perez- } \\
\text { Castillo, Elshabrawy, Filho, } \\
\text { \& de Sousa, 2021; Gowda, } \\
\text { Patrick, Joshi, Kumawat, \& } \\
\text { Sen, 2021; Gurung, Ali, } \\
\text { Lee, Farah, \& Al-Anazi, } \\
\text { 2021; Hejazi, Beg, Imam, } \\
\text { Athar, \& Islam, 2021; Luo } \\
\text { et al., 2020; Muhseen, } \\
\text { Hameed, Al-Hasani, Tahir } \\
\text { ul Qamar, \& Li, 2020; Patil } \\
\text { et al., 2021; H. } \\
\text { Puttaswamy et al., 2020; A. }\end{array}$ \\
\hline
\end{tabular}


Banerjee, Lipsa Rath, \&

Darji, 2021; van de Sand et al., 2021; Vardhan \&

Sahoo, 2020, 2021; Yu et

al., 2021; Z. Zhao et al.,

2021; Zígolo, Goytia,

Poma, Rajal, \& Irazusta 2021)

Kaempferol and analogs

Geranii Herba

Carica papaya

Ephedra sp

Crocus sativus

Senna alexandrina

Broussonetia papyrifera

Moringa oleifera

Mangifera indica

Ginkgo biloba

Justicia adhatoda

\section{Rutin}

Withania somnifera

Passiflora incarnata Theobroma cacao
Polyphenol

\section{SARS-CoV \\ MERS-CoV \\ SARS-CoV-2}

Inhibits SARS-CoV-2 cel

entry via ACE2 receptor

Inhibits proteolytic process,

3CLpro, PLpro, RdRp, Nsp14

Nsp16 and protein S

Polyphenol

SARS-CoV

SARS-CoV-2
3CLpro, PLpro, protein E, Nsp

15, ACE2, Endoribonuclease inhibitor

Reduce cytokines
In silico

In vitro

Arokiyaraj et al., 2020 Du et al., 2021; Gao et al.,

2020; Gheware et al

2021; Hariyono et al.,

2021; Ibrahim et al., 2020;

Mehmood et al., 2021;

Natesh et al., 2021;

Nguyen et al., 2021; Park et al., 2017; $\mathrm{H}$.

Puttaswamy et al., 2020;

Shaji et al., 2021; Singh et al., 2020; Umar et al.

2021; Xiong et al., 2021;

Yañez et al., 2021)

Attia et al., 2021;

In silico

In vitro

Ghosh, Chakraborty,

Chandra, \& Alam, 2021; K.

Ghosh et al., 2021; Kumar

et al., 2021; Kushwaha et

al., 2021; Liu et al., 2020;

Meyer-Almes, 2020;

Nguyen et al., 2021; Niu et

al., 2021; Patil et al., 2021;

Pitsillou, Liang, Hung, et

al., 2021; Pitsillou, Liang 
Curcumin and analogs

Curcuma longa

\section{Myricetin and analogs}

Citrus sinensis

Camellia sinensis

Withania somnifera

Myrica penssylvanica

Isatis indigotica

Torreya nucifera

Moringa oleifera

\section{Apigenin and analogs}

Carica papaya

Hypericum perforatum

Cocos nucifera
Polyphenol

SARS-CoV-2
SARS-CoV
MERS-CoV

Inhibitor of interaction of protein S with GRP78, Mpro, ACE2, proteinS, RdRp

Decrease inflammation

factors and cytokines

Increase the number of reg $\mathrm{T}$ cells

Polyphenol

SARS-CoV-2

Inhibitor of Mpro, Nsp 15,

TMPRSS2, RdRp

Reduce cytokines

In vitro

silico

In vitro

In vivo

Ververis, et al., 2021;

Yañez et al., 2021; Zígolo

$$
\text { et al., 2021) }
$$

Allam et al., 2020; L. Chen et al., 2020; A. Ghosh et al., 2021; Gupta et al., 2020;

Halder et al., 2021;

Ibrahim et al., 2020; Jena et al., 2021; Kodchakorn,

$$
\text { Poovorawan, }
$$

Suwannakarn, \&

Kongtawelert, 2020;

Kumar Verma et al., 2021.

Nguyen et al., 2021; Singh et al., 2020; Tahmasebi et al., 2021: Valizadeh et al 2020; Wen et al., 2007)

(Attia et al., 2021; A. Ghosh al., 2021; K. Ghosh et al., 2021; Gogoi et al., 2021;

Kumar et al., 2021;

Nguyen et al., 2021; Niu et al., 2021; Patil et al., 2021:

H. Puttaswamy et al.,

2020; Singh et al., 2020

Umar et al., 2021; Zígolo et

$$
\text { al., 2021) }
$$

3CLpro, PLpro, RdRp, Nsp 15, ACE2, protein S inhibitor

In silico

In vitro

(Elsbaey et al., 2021;

Fayed et al., 2021;

Gowrishankar et al., 2021.

Hariyono et al., 2021;

Kumar et al., 2021;

Messaoudi et al., 2021;

Natesh et al., 2021;

Nguyen et al., 2021: Ryu et 


\section{Luteolin \\ Ephedra sp \\ Ginkgo biloba}

Justicia adhatoda

\section{Hesperidin and analogs}

Citrus sinensis

Withania somnifera

Isatis indigotica
Polyphenol

SARS-CoV-2
Inhibitor of 3CLpro, PL pro,
ACE2, protein S, Nsp14,
Nsp15, RdRp, TMPRSS2
Reduces cytokines

Polyphenol

SARS-CoV-2

Mpro, Nsp 1,

Endoribonuclease, RdRp,

TMPRSS2, S protein inhibitor

Blocks the 3a channel protein

Reduces ARDS al., 2010; Singh et al., 2020; Xiong et al., 2021;

Yañez et al., 2021)

In silico

In vitro

(Du et al., 2021; Gao et al., 2020; Gheware et al

2021; Kumar et al., 2021;

Liu et al., 2020; Nguyen et

al., 2021; Niu et al., 2021;

Singh et al., 2020; Xiong et

al., 2021; Xu et al., 2021;

Yañez et al., 2021)

In silico

In vitro

(Attia et al., 2021; A. Ghosh

et al., 2021; K. Ghosh et al., 2021; R. Ghosh

Chakraborty, Biswas, \&

Chowdhuri, 2020a; Gupta

et al., 2020; Kodchakorn et al., 2020; Nguyen et al.,

2021; Patil et al., 2021;

Singh et al., 2020; Vardhan

\& Sahoo, 2021; Zígolo et al., 2021) 


\subsection{Antiviral mechanism of action}

Most of the studies on natural substances acting against coronaviruses showed that several metabolites acted by inhibition of the main protease (Mpro) with a percentage of $43.71 \%$, others by inhibition of the viral protein RNA-dependent RNA polymerase (RdRp), the angiotensin converting enzyme (ACE2), the surface protein (protein S) or by the inhibition of the papain-like protein (PLpro). Other studies do not show by which mechanisms these secondary metabolites acted against coronavirus.

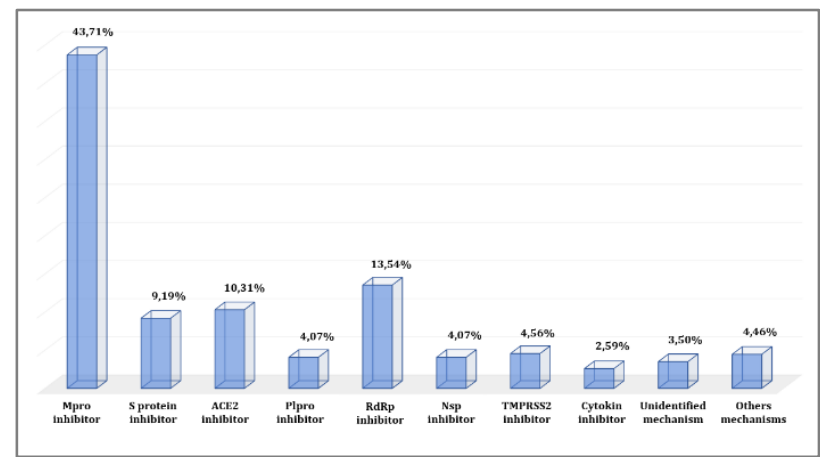

Figure 7. Molecules distribution by action's mechanism.

\subsection{Most cited substances}

Taking into account the citation's frequency in the articles, we ranked the 10 most cited substances (mentionned in more than 3 studies) in descending order (Table 1). Out of these 963 substances, catechins are the most cited compounds (29), followed by quercetin (25), glycyrrhizin (19) and kaempferol (16). The other substances had a lower mention's frequency.

\subsubsection{Polyphenols}

\section{- Quercetin}

Quercetin is a flavonoid widely present in the plant kingdom, found in grapefruit, onions, apples and black tea. A lesser amount exists in green leafy vegetables and beans. Quercetin has a range of pharmacological activities as an antioxidant and anti- inflammatory agent. An experiment confirmed that quercetin could enhance ligand-induced apoptosis of senescent idiopathic pulmonary fibrosis fibroblasts and reduce pulmonary fibrosis in vivo (Xu et al., 2021). In 2017, an in vitro study showed that quercetin and quercetin- $\beta$-galactoside can inhibit the activity of viral proteases (3C-like protease $=3 \mathrm{CL}$ pro and PL pro) of SARS $-\mathrm{CoV}$ and MERS-CoV (Park et al., 2017). In addition, recent studies (in silico and in vitro) have reported the potential inhibitory effects of quercetin and these analogues on the main protease of SARS-CoV-2 (Attia et al., 2021; Kushwaha et al., 2021; Meyer-Almes, 2020; Nguyen et al., 2021; Umar et al., 2021; Xiong et al., 2021).

Another docking technique was also used to further define the inhibitory activity of the glycosides of this flavonol. This technique revealed that quercetin 3,5-digalactoside recorded the lowest binding energy with Mpro. It was observed that flavonols with two glucose moieties recorded lower binding energy (LE) than flavonols with one or three glucose moieties (H. Puttaswamy et al., 2020).

Quercetagenin, another flavonol could effectively inhibit SARS-CoV-2 replication in vitro by $58 \%$ with an IC50 of $145 \mu \mathrm{M}$. It has also been reported that quercetin and quercetin 3-(6-malonylglucoside) could reduce SARS-CoV-2 entry by blocking ACE2 activity (Mesli et al., 2021; Xu et al., 2021). Quercetin analogs can also bind to RdRp and PL pro (Gheware et al., 2021; Singh et al., 2020).

\section{- Rutin}

Rutin flavonoid isolated from the extract of different medicinal plants such as Withania somnifera, Passion flower and Theobroma cacao (A. Ghosh et al., 2021; Yañez et al., 2021) has various biological activities, including anti-inflammatory and antiviral activities. Studies have shown that rutin has 
antimicrobial activity and, through in silico studies, possible inhibitory activity of several proteins essential for SARS-CoV-2 to complete its viral cycle. However, its antiviral spectrum is broader and it is experimentally tested as an antiviral agent against retroviruses, orthomyxoviruses, herpes viruses, hepatitis $B$ and $C$ viruses and H1N1 influenza virus.

Other experiments performed by different researchers mention that rutin can be used as a potential inhibitor of Mpro and ACE2 of COVID-19(Bhowmik et al., 2020; A. Ghosh et al., 2021; Kumar et al., 2021; Meyer-Almes, 2020; Patil et al., 2021; Yañez et al., 2021). In addition, in vitro enzyme inhibition assays also showed that rutin had inhibitory activity against SARS-CoV 3CLpro since the 3CLpro sequence of SARS-CoV-2 is very similar to that of SARS-CoV (Liu et al., 2020; Nguyen et al., 2021).

\section{- Kaempferol}

Kaempferol is a flavonol that can be extracted from several plants namely Moringa oleifera, Carica papaya and Ephedra sp (Gao et al., 2020; Hariyono et al., 2021; Umar et al., 2021). In an in vitro study, kaempferol extracted from Broussonetia papyrifera was identified as an inhibitor of viral proteases (PL pro and 3CL pro) in both SARS-CoV and MERS-CoV (86). Studies have recently begun to focus on SARS-CoV-2 infection, kaempferol and its analogues have been tested against various coronavirus target proteins such as 3CL pro, RdRp, ACE2 and protein $S$ both in silico and in vitro (Du et al., 2021; Gao et al., 2020; Ibrahim et al., 2020; Mehmood et al., 2021; Natesh et al., 2021; Nguyen et al., 2021; Umar et al., 2021; Xiong et al., 2021).

\section{- Myricetin}

Myricetin is a flavonol that can be extracted from Isatis indigotica, Torreya nucifera or Moringa oleifera (M, Reddy, Hema, Dodoala, \& Koganti, 2021; Umar et al., 2021). Myricetin and its analogues have been tested against Mpro, RdRp, Transmembrane serine protease 2 (TMPRSS2), endoribonuclease and IL- 6 both in silico and in vitro. They showed good docking scores especially against TMPRSS2 and RdRp (A. Ghosh et al., 2021; Kumar et al., 2021; M. Reddy et al., 2021; Nguyen et al., 2021; Niu et al., 2021; H. Puttaswamy et al., 2020; Singh et al., 2020; Umar et al., 2021). According to an in vitro study, the absence of hydroxyl groups in the C3 and C4 B-ring was the reason for the lower inhibitory activity of kaempferol and quercetin than myricetin (Nguyen et al., 2021).

\section{- Naringenin}

Naringenin is a flavonone extracted mainly from Citrus fruits, Isatis indigotica. It has been reported as an antiviral agent against Zika virus (Attia et al., 2021; R. Ghosh et al., 2020a; M. Reddy et al., 2021). Naringenin showed no inhibitory effect against Mpro of SARS-CoV (R. Ghosh et al., 2020a). In contrast, it scored good docking against Mpro, TMPRSS2 and RdRp of SARS-CoV-2( M. Reddy et al., 2021; Singh et al., 2020; Yañez et al., 2021). Naringin, a heteroside of naringenin, also showed good scores with Mpro and nonstructural protein 15 (Nsp 15) (Kumar et al., 2021; Yañez et al., 2021).

\section{- Hesperidin}

Hesperidin and its aglycone hesperitin are flavonones extracted mainly from Citrus fruits. Hesperidin has antimicrobial, antiinflammatory, cardiovascular and antidiabetic (Type II) effects (K. Ghosh et al., 2021). Several studies have noted the possible inhibitory activity of hesperidin and hesperitin against various proteins target namely Mpro, TMPRSS2 and RdRp (R. Ghosh et al., 2020a; Kodchakorn et al., 2020; M. Reddy et al., 2021; Nguyen et al., 2021; Singh et al., 2020; Varghese et al., 2021). 
In the flavanones group, the order of M pro inhibitory activity was naringin $<$ hesperidin $<$ naringenin. Naringenin is glycosylated naringin. However, its inhibitory activity was 3.2 times higher than that of naringin. Hesperidin, which contained 7-OH glycosylation at the $\mathrm{A}$ ring like naringenin and the methoxy group at the $5^{\prime}$ position of the $B$ ring, was found to have higher inhibitory activity than naringin but lower inhibitory activity than naringenin, indicating that glycosylation at the C7 position enhanced the inhibitory effect of $M$ pro. In contrast, the methoxy group at $\mathrm{C}^{\prime}$ in the $\mathrm{B}$ ring reduced its inhibitory activity (Nguyen et al., 2021).

\section{- Catechins and gallate catechins}

Catechins are polyphenols, more precisely they are part of the flavonoid family; the subclass of flavanols, present in some foods, including green tea (Camellia sinensis) and Carica papaya. The effect of catechin and its analogues in the inhibition of SARS-CoV-2 associated coronavirus replication has been recently studied and various mechanisms of action have been attributed to the antiviral activities of catechin, such as inhibition of protein S, RdRp, ACE2 and Mpro (R. Ghosh et al., 2020b; Halder et al., 2021; Hariyono et al., 2021; Jena et al., 2021; Meyer-Almes, 2020; Singh et al., 2020).

In an in silico study, catechins extracted from Mangifera indica and Moringa oleifera were identified as potent inhibitors of Mpro with a very high docking score (Umar et al., 2021). In addition, epicatechin is a structural analogue of catechin that exhibits in addition to other inhibitory effects, the ability to inhibit furin, protein $\mathrm{N}$ and Nsp6 (Mishra et al., 2021; Vardhan \& Sahoo, 2021).

Epigallocatechin gallate (EGCG), the main catechin in green tea, is known to exert antiviral activity against several types of viruses including herpes virus, hepatitis virus and influenza A virus. In silico studies to test antiviral activity against SARS-CoV-2 showed that epigallocatechin gallate bound well to key targets including Spike, 3CLpro, PLpro and RdRp (R. Ghosh et al., 2020b; Mhatre et al., 2021). In addition, in vitro studies have confirmed its efficacy in inhibiting replication and reducing cytokine storm (Shin et al., 2021; M. Zhao et al., 2021).

\section{- Curcumin}

Curcumin and its analogues are the main constituents of turmeric (Curcuma longa L.) and other Curcuma spp. which are widely used around the world as a culinary spice, popular dietary supplement ingredient as well as in traditional medicine due to its wide range of health benefits including antiinflammatory, anti-cancer, cardiovascular, respiratory and immune benefits. In addition, the suppression of several cytokines by curcumin has suggested that it may be a useful approach in treating Ebola patients against the cytokine storm. Curcumin has a variety of antiviral activities against dengue virus, herpes simplex virus, Zika virus and chikungunya virus. CC also inhibits aminopeptidase $\mathrm{N}$ (APN) which has been identified as a cellular receptor for alpha $\mathrm{CoV}$ (L. Chen et al., 2020; Halder et al., 2021).

Another study showed that curcumin could effectively inhibit the major protease of SARS-CoV in Vero E6 cells in vitro (Wen et al., 2007). Recently numerous researches have shown its potential inhibitory power against SARS-CoV-2 Mpro both in silico and in vitro (A. Ghosh et al., 2021; Halder et al., 2021). In an in vitro study with curcumin and its analogues, the order of inhibitory effects was bisdemethoxycurcumin $<$ curcumin $<$ dimethylcurcumin. In this group, curcumin contained two methoxy groups ( $\mathrm{C}^{\prime}$ and $\mathrm{C} 4 "$ ) and showed higher inhibitory activity on $\mathrm{M}$ pro than did bisdemethoxycurcumin, which did not have the methoxy group. However, its inhibitory activity was lower than that of dimethylcurcumin, which contained a C2' methoxy group(Nguyen et al., 2021). Two 
double-blind randomized controlled trials showed a significant increase in regulatory $\mathrm{T}$ cells and a decrease in cytokine levels (IL-6, IL-1 $\beta$ ) as well as an attenuation in the mortality rate in severe patients. Curcumin has major problems of water solubility, high metabolism and rapid excretion from the body. This is solved by the nanoscale formulation namely nanocurcumin (Tahmasebi et al., 2021; Valizadeh et al., 2020). Further molecular docking studies revealed that curcumin can also bind to RdRp, ACE2 and protein S (Jena et al., 2021; S. Singh et al., 2020).

\section{- Luteolin}

Luteolin is a flavonoid and more specifically a flavone. It has multiple biological activities, including anti-inflammatory, anti-cancer, anti-oxidant, antiviral and cardiac protective. It has been reported that luteolin can interfere with the virus at the beginning of its life cycle, to some extent blocking the absorption and internalization of the flu virus. In addition, various studies have confirmed that luteolin inhibits the NS2B/NS3 protease activity of the dengue virus. It was also documented that luteolin has an anti-Epstein-Barr virus (EBV) effect. An in silico study showed that luteolin extracted from Ephedra sp and Ginkgo biloba is an inhibitor of SARS-CoV-2 3CLpro. Other studies have also shown that this compound is a potent inhibitor of ACE2 and RdRp. Overall, luteolin has a good antiviral effect, suggesting that luteolin may be a potential drug for the treatment of COVID-19 and their actual effect in the treatment of this disease needs to be verified by further studies (Du et al., 2021; Gao et al., 2020; Kumar et al., 2021; Liu et al., 2020; Singh et al., 2020; Xiong et al., 2021; Yañez et al., 2021).

Luteolin-7-glucoside (Yañez et al., 2021), Luteolin-6-C-arabinosid, Luteolin-6-Cglucoside, Luteolin-6C-glucoside-8Carabinoside and Luteolin-6-8-di-Carabinoside are luteolin analogues isolated from Justicia adhatoda extract (Gheware et al., 2021). They also exhibit antiviral activity against SARS-CoV-2.

\section{- Apigenin}

Apigenin is a compound of the flavonoids family, which has anti-inflammatory properties. An in silico study done by Indonesian researchers on Carica papaya showed the antiviral activity of this natural substance such as the inhbition of Mpro, PLpro and RdRp. In addition, several studies on different apigenin analogues such as Apigeninidin 5-0-glucoside, apigenidin and 6,6'-biapigenin have shown their antiviral efficacy against SARS-CoV-2 via inhibition of Mpro and RdRp (Elsbaey et al., 2021; Ryu et al., 2010).

\section{- Caffeic acid}

Caffeic acid is a polyphenol, naturally present in all plants as it is a key intermediate in lignin biosynthesis. An in silico study by Indonesian researchers showed that caffeic acid extracted from Carica papaya decreases the inflammatory factors of SARS-CoV-2 (Hariyono et al., 2021). Other in silico studies have confirmed that this compound acts as an inhibitor of Mpro and RdRp (Adem et al., 2021; Bhowmik et al., 2020; Kumar et al., 2021; Nguyen et al., 2021; Singh et al., 2020; Umar et al., 2021; Yañez et al., 2021).

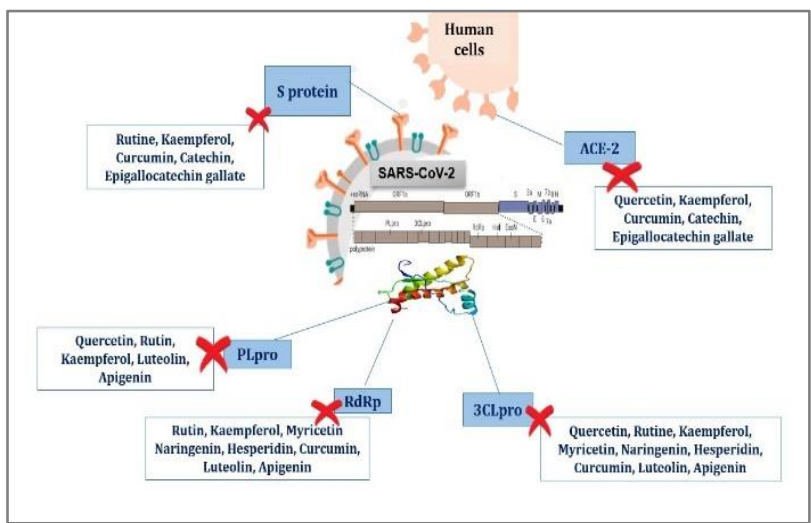

Figure 8. Polyphenols and Anti-SARS-CoV-2 inhbition's mechanisms 


\subsubsection{Terpenes}

\section{- Glycyrrhizin}

Glycyrrhizin also called glycyrrhizic acid is a triterpene saponin extracted mainly from the root of Glycyrrhiza glabra (licorice) and Glycyrrhiza uralensis. A large number of studies have shown that licorice and its components have a protective effect on inflammation and lung damage and it is a promising medicinal plant for the treatment of SARS infections. In addition, glycyrrhizin was active against other viruses such as varicella-zoster virus, herpes simplex virus and dengue virus. It is an effective hepatoprotective substance in patients with chronic hepatitis $C$ and can protect against a variety of liver diseases such as chronic viral hepatitis, drug-induced and chemicalinduced liver damage, non-alcoholic fatty liver, autoimmune hepatitis and hepatocellular carcinoma. It is also used for the treatment of skin inflammation.

The effect of glycyrrhizin in inhibiting the replication of SARS-CoV-2 associated coronavirus has been recently studied and various mechanisms of action have been attributed to the antiviral activities of glycyrrhizin, such as inhibition of endoribonuclease (Patil et al., 2021), inhibition of Mpro, PLpro, RBD, RdRp and ACE2, inhibition of protein $S$ and accessory protein Nsp1 and inhibition of TMPRSS2 (Muhseen et al., 2020; H. Puttaswamy et al., 2020; A. Sharma et al., 2020; Toor et al., 2021; van de Sand et al., 2021; Vardhan \& Sahoo, 2020; Yu et al., 2021). In addition, glycyrrhyzin plays an important role in inhibiting immune hyperactivation and the development of cytokine storm factors (Yu et al., 2021).

$18 \beta$-glycyrrhetinic acid is active against SARS-CoV, SARS-CoV-2 and MERS-CoV by acting on the inhibition of Mpro (Diniz et al., 2021; Vardhan \& Sahoo, 2021; Zígolo et al.,
2021). Glycyrrhetinic acid is the aglycone of glycyrrhizin (Luo et al., 2020).

\section{- Andrographolide}

Andrographolide is the major active component isolated from the extract of the herb Andrographis paniculata (Banerjee et al., 2021; Sa-Ngiamsuntorn et al., 2021). This labdane-type diterpene lactone possesses a wide range of biological activities, including antiviral, antibacterial, antiparasitic, antitumor, and promotive antidiabetic potential. Previous studies have shown that andrographolide possesses a broad spectrum of antiviral properties, which inhibits various viral infections, including influenza A virus, human immunodeficiency virus (HIV), Chikungunya virus (CHIKV), dengue virus (DENV) by acting on GRP78 and Enterovirus D68 (EV-D68. Andrographolide induces endoplasmic reticulum (ER) stress leading to cancer cell death by apoptosis via induction of increased levels of reactive oxygen species (ROS) that can inhibit virus-induced carcinogenesis (Shi et al., 2020). Additional inhibitory effects of andrographolide include those of cell migration, invasion, matrix metalloproteinase expression, antiangiogenesis, autophagy, and pathway dysregulation have been reported for inflammatory disorders, including cancer.

In addition, in silico studies to test antiviral activity against SARS-CoV-2 also showed that andrographolide bound well to key targets, including Spike protein, 3CLpro, and PLpro, indicating that andrographolide has potential efficacy against SARS-CoV-2 (Banerjee et al., 2021; Kodchakorn et al., 2020; SaNgiamsuntorn et al., 2021; Shi et al., 2020; Verma et al., 2021). Overall, as a plantderived compound, andrographolide is widely distributed with low cytotoxicity, but its potent antiviral activity against a variety of viruses requires further investigation. 


\section{- Artemisinin}

Artemisinin is the main active component of Artemisia annua. It is a sesquiterpenic lactone. Artemisinin is an ancient antimalarial drug, has saved millions of lives, and has been reported to have multiple pharmacological activities, including anticancer, antiviral and immune modulation.

In an in vitro study, artemisinin was chosen to test their anti-SARS-CoV-2 potential using African green monkey kidney Vero E6 cells. Cytotoxicity assays were performed prior to the antiviral assay to determine the cytotoxicity of the selected compounds, and viral RNA copies in the supernatants were determined by quantitative real-time PCR (qRT-PCR) to determine the antiviral effects of the compounds. The results of this study show that artemisinin and its derivatives: Arteannuine B showed the highest antiSARS-CoV-2 potential with an EC50 of 10.28 $\pm 1.12 \mathrm{M}$.

Artesunate and dihydroartemisinin showed similar EC50 values of $12.98 \pm 5.30 \mathrm{M}$ and $13.31 \pm 1.24 \mathrm{M}$, respectively, which could be achieved clinically in plasma after intravenous administration. Further mode of action analysis revealed that arteannuine $\mathrm{B}$ and lumefantrine acted in the post-entry stage of SARS-CoV-2 infection. This research highlights the anti-SARS-CoV-2 potential of artemisinin and provides leading candidates for anti-SARS-CoV-2 drug research and development (Cao et al., 2020). Other in silico studies have shown that this chemical compound is a potent inhibitor of BRD2 and the accessory protein Nsp1(Aydın, Altınel, Erdoğmuş, \& Son Ç, 2021; Gupta et al., 2020; Li et al., 2021).

\subsubsection{Alkaloids}

Since the discovery of this class of natural products, several biological activities associated with alkaloids have been reported, including analgesic, antibacterial, antifungal, anti-inflammatory, anticancer and antiviral. Among the alkaloids that have antiviral activity is berberine (Fielding, da Silva Maia Bezerra Filho, Ismail, \& Sousa, 2020).

\section{- Berberin}

Berberin is an isoquinoline alkaloid derived from the Chinese herb Coptis chinensis and plants of the genus Berberis. Its broad biological properties identified in preclinical studies include anti-inflammatory, antiarrhythmic, antimicrobial and cholesterollowering activity. Berberin has broadspectrum antiviral activity in vitro against viruses from several different families, including influenza A virus, enterovirus, chikungunya virus, hepatitis $B$ and $C$ viruses, HIV, respiratory syncytial virus, human cytomegalovirus, herpes simplex virus, and human papilloma virus (Varghese et al., 2021).

In one study, Berberin showed good binding activities to the S1 subunit of SARS-CoV-2. Then, to determine whether this compound may be a candidate for broad-spectrum anticoronavirus activity, they performed further evaluation on the S1 subunits of MERS-CoV and SARS-CoV. The results showed similar binding activity with the S1 subunit of MERSCoV but reduced affinity for SARS-CoV(Yu et al., 2021). In addition, Berberin showed good docking scores against Mpro and Nsp 15 (Kumar et al., 2021; Zígolo et al., 2021).

Another study identified potential therapeutic targets for berberine against SARS-CoV and SARS-CoV-2 using computer modeling. The most important targets for berberine include NF- $\mathrm{BB}$ and MAPK, which are cytokine storm-regulating proteins, and CASP and BAX, which are relevant targets for preventing tissue damage by suppressing cell death signaling pathways. Thus, they demonstrated for the first time that berberin significantly reduces viral replication, suppresses viral entry of the host receptor 
ACE2 and TMPRSS2, and decreases inflammatory markers, including IL-6, IL-8, IL-1 $\alpha$, and CCL2 in SARS-CoV-2-infected Calu3 cells (Wang et al., 2021). Berberin has also shown efficacy against SARS-CoV-2 at low micromolar concentrations in vitro in Vero E6 cells (Varghese et al., 2021). In a randomized controlled trial of 39 hospitalized patients with severe COVID-19 grouped into 2 groups, the first received berberin plus routine treatment within 14 days of admission and the control group received only routine treatment. No significant differences were observed between the 2 groups in the trend of IL- 6 , TNF- $\alpha$, CRP, procalcitonin, and white blood cell levels within 14 days. In subgroup analyses of patients with diarrhea, berberine significantly improved changes in IL-6, TNF$\alpha$, and CRP levels. They hypothesized that berberin may reduce serum levels of inflammatory mediators through the protection and maintenance of gastrointestinal function (Zhang et al., 2021).

\section{Conclusion}

Natural products have long been used as a treasure trove of drug discovery. These structurally diverse molecules exert a wide range of pharmacological activities, including exceptional antiviral activity. Considerable effort has been devoted to the development of anti-coronavirus drugs from natural products, particularly in the context of global public health challenges such as the SARSCoV outbreaks in 2003 and the current SARSCoV-2. In order to provide a more systematic understanding of the research on anticoronavirus activity of natural products, we have reviewed the relevant studies to date, and summarized the properties of many natural bioactive molecules according to their chemical family, mechanism of action... Most of these natural products are listed as inhibitors against SARS-CoV and SARS-CoV-2 and some molecules act on MERS-CoV.

This study compiled data on different types of phytoconstituents with antiviral activity against coronaviruses as well as phytoconstituents with affinities against SARS-CoV-2 therapeutic targets such as RdRP, 3CLpro, PLpro and host cell targets such as ACE-2, mainly based on computational screening methods. Among these substances, polyphenols, terpenes and alkaloids showed very encouraging anticoronavirus activity, which could provide a large number of promising candidates for anti-coronavirus drug development and offer potential weapons against SARS-CoV-2 in the current dilemma.

However, further in vivo and in vitro studies are needed to confirm the bioactivity of these compounds against COVID-19.

Overall, the development of phytopharmaceuticals as an alternative approach could be considered a viable therapeutic option against SARS-CoV-2 in the current COVID-19 pandemic.

\section{Acknowledgements}

This work was supported by the Departement of pharmacy, Faculty of Medecine, ABOU BEKR BELKAID University, Tlemcen, Algeria.

\section{Author Contribution}

Amal HELALI and Khadidja BENCHACHOU conceived and designed the study. Meryem Wafa HAMMADI and Manel HOUALEF performed the data research and exploitation. Amal HELALI wrote the paper.

\section{Conflicts of Interest}

The authors declare that the research was conducted in the absence of any commercial or financial relationships that could be construed as a potential conflict of interest.

\section{References}

1. Adem, S.., Eyupoglu, V., Sarfraz, I., Rasul, A., Zahoor, A. F., Ali, M., ... Elfiky, A. A. (2021). Caffeic acid derivatives (CAFDs) as inhibitors of SARSCoV-2: CAFDs-based functional foods as a potential alternative approach to combat COVID- 
19. Phytomedicine, 85, 153310. doi:https://doi.org/10.1016/i.phymed.2020.153 $\underline{310}$

2. Allam, L., Ghrifi, F., Mohammed, H., El Hafidi, N., El Jaoudi, R., El Harti, J., . . . Ibrahimi, A. (2020). Targeting the GRP78-Dependant SARS-CoV-2 Cell Entry by Peptides and Small Molecules. Bioinformatics and Biology Insights, 14, 1177932220965505. doi:10.1177/1177932220965505

3. Arokiyaraj, S., Stalin, A., Kannan, B. S., \& Shin, H. (2020). Geranii Herba as a Potential Inhibitor of SARS-CoV-2 Main 3CL(pro), Spike RBD, and Regulation of Unfolded Protein Response: An In Silico Approach. Antibiotics (Basel), 9(12). doi:10.3390/antibiotics9120863

4. Asrani, P., Hasan, G. M., Sohal, S. S., \& Hassan, M. I. (2020). Molecular Basis of Pathogenesis of Coronaviruses: A Comparative Genomics Approach to Planetary Health to Prevent Zoonotic Outbreaks in the 21st Century. Omics, 24(11), 634-644. doi:10.1089/omi.2020.0131

5. Attia, G. H., Moemen, Y. S., Youns, M., Ibrahim, A. M., Abdou, R., \& El Raey, M. A. (2021). Antiviral zinc oxide nanoparticles mediated by hesperidin and in silico comparison study between antiviral phenolics as anti-SARS-CoV-2. Colloids and Surfaces B: Biointerfaces, 203, 111724. doi:https://doi.org/10.1016/j.colsurfb.2021.111 $\underline{724}$

6. Aydın, A. D., Altınel, F., Erdoğmuş, H., \& Son Ç, D. (2021). Allergen fragrance molecules: a potential relief for COVID-19. BMC Complementary Medecine and Therapies, 21(1), 41. doi:10.1186/s12906-021-03214-4

7. Azim, K. F., Ahmed, S. R., Banik, A., Khan, M. M. R., Deb, A., \& Somana, S. R. (2020). Screening and druggability analysis of some plant metabolites against SARS-CoV-2: An integrative computational approach. Informatics in Medecine Unlocked, 20, 100367. doi:https://doi.org/10.1016/j.imu.2020.100367

8. Banerjee, S., Kar, A., Mukherjee, P. K., Haldar, P. K., Sharma, N., \& Katiyar, C. K. (2021). Immunoprotective potential of Ayurvedic herb Kalmegh (Andrographis paniculata) against respiratory viral infections - LC-MS/MS and network pharmacology analysis. Phytochemical Analysis, 32(4), 629-639. doi:10.1002/pca.3011

9. Bhowmik, D., Nandi, R., Jagadeesan, R., Kumar, N., Prakash, A., \& Kumar, D. (2020). Identification of potential inhibitors against SARS-CoV-2 by targeting proteins responsible for envelope formation and virion assembly using docking based virtual screening, and pharmacokinetics approaches. Infection, Genetics and Evolution, 84, 104451.

doi:https://doi.org/10.1016/j.meegid.2020.104 $\underline{451}$
10. Cao, R., Hu, H., Li, Y., Wang, X., Xu, M., Liu, J., . . . Zhong, W. (2020). Anti-SARS-CoV-2 Potential of Artemisinins In Vitro. ACS Infectious Diseases, 6(9),

2524-2531. doi:10.1021/acsinfecdis.0c00522

11. Chen, F., Chan, K. H., Jiang, Y., Kao, R. Y., Lu, H. T., Fan, K. W., . . . Yuen, K. Y. (2004). In vitro susceptibility of 10 clinical isolates of SARS coronavirus to selected antiviral compounds. Journal of Clinical Virology, 31(1), 69-75. doi:10.1016/j.jcv.2004.03.003

12. Chen, L., Hu, C., Hood, M., Zhang, X., Zhang, L., Kan, J., \& Du, J. (2020). A Novel Combination of Vitamin C, Curcumin and Glycyrrhizic Acid Potentially Regulates Immune and Inflammatory Response Associated with Coronavirus Infections: A Perspective from System Biology Analysis. Nutrients, 12(4). doi:10.3390/nu12041193

13. Ding, H., Deng, W., Ding, L., Ye, X., Yin, S., \& Huang, W. (2020). Glycyrrhetinic acid and its derivatives as potential alternative medicine to relieve symptoms in nonhospitalized COVID-19 patients. Journal of Med Virology, 92(10), 2200-2204. doi:10.1002/jmv.26064

14. Diniz, L. R. L., Perez-Castillo, Y., Elshabrawy, H. A., Filho, C., \& de Sousa, D. P. (2021). Bioactive Terpenes and Their Derivatives as Potential SARS-CoV-2 Proteases Inhibitors from Molecular Modeling Studies. Biomolecules, 11(1). doi:10.3390/biom11010074

15. Du, A., Zheng, R., Disoma, C., Li, S., Chen, Z., Li, S., . .. Xia, Z. (2021). Epigallocatechin-3-gallate, an active ingredient of Traditional Chinese Medicines, inhibits the 3CLpro activity of SARSCoV-2. International journal of biological macromolecules, 176, 1-12. doi:10.1016/j.ijbiomac.2021.02.012

16. Elsbaey, M., Ibrahim, M. A. A., Bar, F. A., \& Elgazar, A. A. (2021). Chemical constituents from coconut waste and their in silico evaluation as potential antiviral agents against SARS-CoV-2. South African Journal of Botany, 141, 278-289. doi:https://doi.org/10.1016/j.sajb.2021.05.018

17. Fayed, M. A. A., El-Behairy, M. F., Abdallah, I. A., Abdel-Bar, H. M., Elimam, H., Mostafa, A., . . . Elshaier, Y. A. M. M. (2021). Structure- and Ligand-Based in silico Studies towards the Repurposing of Marine Bioactive Compounds to Target SARS-CoV-2. Arabian Journal of Chemistry, 14(4), 103092. doi:https://doi.org/10.1016/i.arabjc.2021.1030 $\underline{92}$

18. Fielding, B. C., da Silva Maia Bezerra Filho, C., Ismail, N. S. M., \& Sousa, D. P. (2020). Alkaloids: Therapeutic Potential against Human Coronaviruses. Molecules, 25(23). doi:10.3390/molecules25235496

19. Gao, K., Song, Y.-P., \& Song, A. (2020). Exploring active ingredients and function mechanisms of 
Ephedra-bitter almond for prevention and treatment of Corona virus disease 2019 (COVID19) based on network pharmacology. BioData Mining, 13(1), 19. doi:10.1186/s13040-02000229-4

20. Gheware, A., Dholakia, D., Kannan, S., Panda, L., Rani, R., Pattnaik, B. R., . . . Prasher, B. (2021). Adhatoda Vasica attenuates inflammatory and hypoxic responses in preclinical mouse models: potential for repurposing in COVID-19-like conditions. Respiratory Research, 22(1), 99. doi:10.1186/s12931-021-01698-9

21. Ghosh, A., Chakraborty, M., Chandra, A., \& Alam, M. P. (2021). Structure-activity relationship (SAR) and molecular dynamics study of withaferin-A fragment derivatives as potential therapeutic lead against main protease (M(pro)) of SARS-CoV-2. Journal of Molecular Modeling, 27(3), 97. doi:10.1007/s00894-021-04703-6

22. Ghosh, K., Amin, S. A., Gayen, S., \& Jha, T. (2021). Chemical-informatics approach to COVID-19 drug discovery: Exploration of important fragments and data mining based prediction of some hits from natural origins as main protease (Mpro) inhibitors. Journal of Molecular Structure, 1224, 129026. doi:https://doi.org/10.1016/j.molstruc.2020.12 $\underline{9026}$

23. Ghosh, R., Chakraborty, A., Biswas, A., \& Chowdhuri, S. (2020a). Depicting the inhibitory potential of polyphenols from Isatis indigotica root against the main protease of SARS CoV-2 using computational approaches. Journal of Biomolecular Structure and Dynamics, 1-12. doi:10.1080/07391102.2020.1858164

24. Ghosh, R., Chakraborty, A., Biswas, A., \& Chowdhuri, S. (2020b). Evaluation of green tea polyphenols as novel corona virus (SARS CoV-2) main protease (Mpro) inhibitors - an in silico docking and molecular dynamics simulation study. Journal of Biomolecular Structure and Dynamics, 1-13. doi:10.1080/07391102.2020.1779818

25. Gogoi, B., Chowdhury, P., Goswami, N., Gogoi, N., Naiya, T., Chetia, P., . . . Handique, P. J. (2021). Identification of potential plant-based inhibitor against viral proteases of SARS-CoV-2 through molecular docking, MM-PBSA binding energy calculations and molecular dynamics simulation. Molecular Diversity, 1-15. doi:10.1007/s11030021-10211-9

26. Gowda, P., Patrick, S., Joshi, S. D., Kumawat, R. K., \& Sen, E. (2021). Glycyrrhizin prevents SARSCoV-2 S1 and Orf3a induced high mobility group box 1 (HMGB1) release and inhibits viral replication. Cytokine, 142, 155496. doi:10.1016/j.cyto.2021.155496

27. Gowrishankar, S., Muthumanickam, S., Kamaladevi, A., Karthika, C., Jothi, R., Boomi, P., . .
. Pandian, S. K. (2021). Promising phytochemicals of traditional Indian herbal steam inhalation therapy to combat COVID-19 - An in silico study. Food and Chemical Toxicology, 148, 111966. doi:https://doi.org/10.1016/j.fct.2020.111966

28. Gupta, S., Singh, V., Varadwaj, P. K., Chakravartty, N., Katta, A., Lekkala, S. P., ... Reddy Lachagari, V. B. (2020). Secondary metabolites from spice and herbs as potential multitarget inhibitors of SARSCoV-2 proteins. Journal of Biomolecular Structure and Dynamics, 1-20. doi:10.1080/07391102.2020.1837679

29. Gurung, A. B., Ali, M. A., Lee, J., Farah, M. A., \& AlAnazi, K. M. (2021). The potential of Paritaprevir and Emetine as inhibitors of SARS-CoV-2 RdRp. Saudi Journal of Biological Sciences, 28(2), 14261432.

doi:https://doi.org/10.1016/j.sjbs.2020.11.078

30. Halder, P., Pal, U., Paladhi, P., Dutta, S., Paul, P., Pal, S., . . Ghosh, S. (2021). Evaluation of potency of the selected bioactive molecules from Indian medicinal plants with MPro of SARS-CoV-2 through in silico analysis. Journal of Ayurveda and Integrative Medicine. doi:https://doi.org/10.1016/j.jaim.2021.05.003

31. Hariyono, P., Patramurti, C., Candrasari, D. S., \& Hariono, M. (2021). An integrated virtual screening of compounds from Carica papaya leaves against multiple protein targets of SARSCoronavirus-2. Results in chemistry, 3, 100113100113. doi:10.1016/j.rechem.2021.100113

32. Hejazi, I. I., Beg, M. A., Imam, M. A., Athar, F., \& Islam, A. (2021). Glossary of phytoconstituents: Can these be repurposed against SARS CoV-2? A quick in silico screening of various phytoconstituents from plant Glycyrrhiza glabra with SARS CoV-2 main protease. Food and Chemical Toxicology, 150, 112057. doi:https://doi.org/10.1016/j.fct.2021.112057

33. Ibrahim, M. A. A., Abdelrahman, A. H. M., Hussien, T. A., Badr, E. A. A., Mohamed, T. A., El-Seedi, H. R., . . Hegazy, M.-E. F. (2020). In silico drug discovery of major metabolites from spices as SARS-CoV-2 main protease inhibitors. Computers in Biology and Medecine, 126, 104046. doi:https://doi.org/10.1016/j.compbiomed.202 $\underline{0.104046}$

34. Jang, M., Park, R., Park, Y. I., Cha, Y. E., Yamamoto, A., Lee, J. I., \& Park, J. (2021). EGCG, a green tea polyphenol, inhibits human coronavirus replication in vitro. Biochemical and Biophysical Research Communications, 547, 23-28. doi:10.1016/j.bbrc.2021.02.016

35. Jang, M., Park, Y. I., Cha, Y. E., Park, R., Namkoong, S., Lee, J. I., \& Park, J. (2020). Tea Polyphenols EGCG and Theaflavin Inhibit the Activity of SARSCoV-2 3CL-Protease In Vitro. Evidence-based Complementary and Alternative Medicine, 2020, 5630838. doi:10.1155/2020/5630838 
36. Jena, A. B., Kanungo, N., Nayak, V., Chainy, G. B. N., \& Dandapat, J. (2021). Catechin and curcumin interact with S protein of SARS-CoV2 and ACE2 of human cell membrane: insights from computational studies. Scientific Reports, 11(1), 2043. doi:10.1038/s41598-021-81462-7

37. Kodchakorn, K., Poovorawan, Y., Suwannakarn, K., \& Kongtawelert, P. (2020). Molecular modelling investigation for drugs and nutraceuticals against protease of SARS-CoV-2. Journal of Molecular Graphics \& Modelling, 101, 107717. doi:10.1016/j.jmgm.2020.107717

38. Kumar, S., Kashyap, P., Chowdhury, S., Kumar, S., Panwar, A., \& Kumar, A. (2021). Identification of phytochemicals as potential therapeutic agents that binds to Nsp15 protein target of coronavirus (SARS-CoV-2) that are capable of inhibiting virus replication. Phytomedicine, 85, 153317. doi:10.1016/j.phymed.2020.153317

39. Kumar Verma, A., Kumar, V., Singh, S., Goswami, B. C., Camps, I., Sekar, A., ... Lee, K. W. (2021). Repurposing potential of Ayurvedic medicinal plants derived active principles against SARSCoV-2 associated target proteins revealed by molecular docking, molecular dynamics and MMPBSA studies. Biomedicine and Pharmacotherapy, 137, 111356. doi:10.1016/j.biopha.2021.111356

40. Kushwaha, P. P., Singh, A. K., Prajapati, K. S., Shuaib, M., Gupta, S., \& Kumar, S. (2021). Phytochemicals present in Indian ginseng possess potential to inhibit SARS-CoV-2 virulence: A molecular docking and MD simulation study. Microbial Pathogenesis, 157, 104954.

doi:https://doi.org/10.1016/j.micpath.2021.104 $\underline{954}$

41. Li, G., Yuan, M., Li, H., Deng, C., Wang, Q., Tang, Y., . . . Song, J. (2021). Safety and efficacy of artemisinin-piperaquine for treatment of COVID19: an open-label, non-randomised and controlled trial. International Journal of Antimicrobial Agents, 57(1), 106216. doi:10.1016/j.ijantimicag.2020.106216

42. Liu, X., Raghuvanshi, R., Ceylan, F. D., \& Bolling, B. W. (2020). Quercetin and Its Metabolites Inhibit Recombinant Human Angiotensin-Converting Enzyme 2 (ACE2) Activity. Journal of Agricultural and Food Chemistry, 68(47), 13982-13989. doi:10.1021/acs.jafc.0c05064

43. Luo, L., Jiang, J., Wang, C., Fitzgerald, M., Hu, W., Zhou, Y., . . Chen, S. (2020). Analysis on herbal medicines utilized for treatment of COVID-19. Acta Pharmaceutica Sinica B, 10(7), 1192-1204. doi:https://doi.org/10.1016/i.apsb.2020.05.007

44. M, P., Reddy, G. J., Hema, K., Dodoala, S., \& Koganti, B. (2021). Unravelling high-affinity binding compounds towards transmembrane protease serine 2 enzyme in treating SARS-CoV-2 infection using molecular modelling and docking studies.
European Journal of Pharmacology, 890, 173688. doi:https://doi.org/10.1016/i.ejphar.2020.1736 $\underline{88}$

45. Mehmood, A., Khan, S., Khan, S., Ahmed, S., Ali, A., xue, M., . . . Bai, Q. (2021). In silico analysis of quranic and prophetic medicinals plants for the treatment of infectious viral diseases including corona virus. Saudi Journal of Biological Sciences, 28(5), 3137-3151. doi:https://doi.org/10.1016/j.sjbs.2021.02.058

46. Mesli, F., Ghalem, M., Daoud, I., \& Ghalem, S. (2021). Potential inhibitors of angiotensin converting enzyme 2 receptor of COVID-19 by Corchorus olitorius Linn using docking, molecular dynamics, conceptual DFT investigation and pharmacophore mapping. Journal of Biomolecular Structure and Dynamics, 1-13. doi:10.1080/07391102.2021.1896389

47. Messaoudi, O., Gouzi, H., El-Hoshoudy, A. N., Benaceur, F., Patel, C., Goswami, D., ... Bendahou, M. (2021). Berries anthocyanins as potential SARS-CoV-2 inhibitors targeting the viral attachment and replication; molecular docking simulation. Egyptian Journal of Petroleum, 30(1), 33-43.

doi:https://doi.org/10.1016/i.ejpe.2021.01.001

48. Meyer-Almes, F.-J. (2020). Repurposing approved drugs as potential inhibitors of 3CLprotease of SARS-CoV-2: Virtual screening and structure based drug design. Computational Biology and Chemistry, 88, 107351. doi:https://doi.org/10.1016/j.compbiolchem.20 $\underline{20.107351}$

49. Mhatre, S., Naik, S., \& Patravale, V. (2021). A molecular docking study of EGCG and theaflavin digallate with the druggable targets of SARS-CoV2. Computers in Biology and Medicine, 129, 104137. doi:10.1016/j.compbiomed.2020.104137

50. Mishra, C. B., Pandey, P., Sharma, R. D., Malik, M. Z., Mongre, R. K., Lynn, A. M., . . . Prakash, A. (2021). Identifying the natural polyphenol catechin as a multi-targeted agent against SARSCoV-2 for the plausible therapy of COVID-19: an integrated computational approach. Briefings in Bioinformatics, 22(2), 1346-1360. doi:10.1093/bib/bbaa378

51. Muhseen, Z. T., Hameed, A. R., Al-Hasani, H. M. H., Tahir ul Qamar, M., \& Li, G. (2020). Promising terpenes as SARS-CoV-2 spike receptor-binding domain (RBD) attachment inhibitors to the human ACE2 receptor: Integrated computational approach. Journal of Molecular Liquids, 320, 114493.

doi:https://doi.org/10.1016/i.molliq.2020.1144 $\underline{93}$

52. Natesh, J., Mondal, P., Kaur, B., Abdul Salam, A. A., Kasilingam, S., \& Meeran, S. M. (2021). Promising phytochemicals of traditional Himalayan 
medicinal plants against putative replication and transmission targets of SARS-CoV-2 by computational investigation. Computers in Biology and Medicine, 133, 104383. doi:https://doi.org/10.1016/i.compbiomed.202 1.104383

53. Nguyen, T. T. H., Jung, J. H., Kim, M. K., Lim, S., Choi, J. M., Chung, B., ... Kim, D. (2021). The Inhibitory Effects of Plant Derivate Polyphenols on the Main Protease of SARS Coronavirus 2 and Their Structure-Activity Relationship. Molecules, 26(7). doi:10.3390/molecules26071924

54. Niu, W. H., Wu, F., Cao, W. Y., Wu, Z. G., Chao, Y. C., \& Liang, C. (2021). Network pharmacology for the identification of phytochemicals in traditional Chinese medicine for COVID-19 that may regulate interleukin-6. Bioscience Reports, 41(1). doi:10.1042/bsr20202583

55. Park, J. Y., Yuk, H. J., Ryu, H. W., Lim, S. H., Kim, K. S., Park, K. H., ... Lee, W. S. (2017). Evaluation of polyphenols from Broussonetia papyrifera as coronavirus protease inhibitors. Journal of Enzyme Inhibition and Medicinal Chemistry, 32(1), 504-515. doi:10.1080/14756366.2016.1265519

56. Patil, R., Chikhale, R., Khanal, P., Gurav, N., Ayyanar, M., Sinha, S., . . Gurav, S. S. (2021). Computational and network pharmacology analysis of bioflavonoids as possible natural antiviral compounds in COVID-19. Informatics in Medicine Unlocked, 22, 100504. doi:10.1016/j.imu.2020.100504

57. Pitsillou, E., Liang, J., Hung, A., \& Karagiannis, T. C. (2021). Inhibition of interferon-stimulated gene 15 and lysine 48-linked ubiquitin binding to the SARS-CoV-2 papain-like protease by small molecules: In silico studies. Chemical Physics Letters, $\quad 771, \quad 138468$. doi:https://doi.org/10.1016/j.cplett.2021.1384 $\underline{68}$

58. Pitsillou, E., Liang, J., Ververis, K., Hung, A., \& Karagiannis, T. C. (2021). Interaction of small molecules with the SARS-CoV-2 papain-like protease: In silico studies and in vitro validation of protease activity inhibition using an enzymatic inhibition assay. Journal of Molecular Graphics and Modelling, 104, 107851. doi:https://doi.org/10.1016/i.jmgm.2021.1078 $\underline{51}$

59. Puttaswamy, H., Gowtham, H. G., Ojha, M. D., Yadav, A., Choudhir, G., Raguraman, V., . . . Chauhan, L. (2020). In silico studies evidenced the role of structurally diverse plant secondary metabolites in reducing SARS-CoV-2 pathogenesis. Scientific Reports, 10(1), 20584. doi:10.1038/s41598-020-77602-0

60. Puttaswamy, H., Gowtham, H. G., Ojha, M. D., Yadav, A., Choudhir, G., Raguraman, V., . . . Chauhan, L. (2020). In silico studies evidenced the role of structurally diverse plant secondary metabolites in reducing SARS-CoV-2 pathogenesis. Scientific Reports, 10(1), 20584. doi:10.1038/s41598-020-77602-0

61. Roh, C. (2012). A facile inhibitor screening of SARS coronavirus $\mathrm{N}$ protein using nanoparticlebased RNA oligonucleotide. International journal of nanomedicine, 7, 2173-2179. doi:10.2147/IJN.S31379

62. Ryu, Y. B., Jeong, H. J., Kim, J. H., Kim, Y. M., Park, J.-Y., Kim, D., ... Lee, W. S. (2010). Biflavonoids from Torreya nucifera displaying SARS-CoV 3CLpro inhibition. Bioorganic \& Medicinal Chemistry, 18(22), 7940-7947. doi:https://doi.org/10.1016/i.bmc.2010.09.035

63. Sa-Ngiamsuntorn, K., Suksatu, A., Pewkliang, Y., Thongsri, $\quad$., $\quad$ Kanjanasirirat, P., Manopwisedjaroen, S., . . . Hongeng, S. (2021). Anti-SARS-CoV-2 Activity of Andrographis paniculata Extract and Its Major Component Andrographolide in Human Lung Epithelial Cells and Cytotoxicity Evaluation in Major Organ Cell Representatives. Journal of Natural Products, 84(4),

1261-1270. doi:10.1021/acs.jnatprod.0c01324

64. Shaji, D., Yamamoto, S., Saito, R., Suzuki, R., Nakamura, S., \& Kurita, N. (2021). Proposal of novel natural inhibitors of severe acute respiratory syndrome coronavirus 2 main protease: Molecular docking and ab initio fragment molecular orbital calculations. Biophysical Chemistry, 275, 106608. doi:https://doi.org/10.1016/j.bpc.2021.106608

65. Sharma, A., Tiwari, V., \& Sowdhamini, R. (2020). Computational search for potential COVID-19 drugs from FDAapproved drugs and small molecules of natural origin identifies several antivirals and plant products. Journal of Biosciences, 45(1). doi:10.1007/s12038-020-00069-8

66. Sharma, P., \& Shanavas, A. (2020). Natural derivatives with dual binding potential against SARS-CoV-2 main protease and human ACE2 possess low oral bioavailability: a brief computational analysis. Journal of Biomolecular Structure and Dynamics, 1-12. doi:10.1080/07391102.2020.1794970

67. Shi, T. H., Huang, Y. L., Chen, C. C., Pi, W. C., Hsu, Y. L., Lo, L. C., ... Lin, C. H. (2020). Andrographolide and its fluorescent derivative inhibit the main proteases of 2019-nCoV and SARS-CoV through covalent linkage. Biochemical and Biophysical Research Communications, 533(3), 467-473. doi:10.1016/j.bbrc.2020.08.086

68. Shin, J. A., Oh, S., \& Jeong, J.-M. (2021). The potential of BEN815 as an anti-inflammatory, antiviral and antioxidant agent for the treatment of COVID-19. Phytomedicine Plus, 1(4), 100058. doi:https://doi.org/10.1016/i.phyplu.2021.100 $\underline{058}$ 
69. Singh, S., Sk, M. F., Sonawane, A., Kar, P., \& Sadhukhan, S. (2020). Plant-derived natural polyphenols as potential antiviral drugs against SARS-CoV-2 via RNA-dependent RNA polymerase (RdRp) inhibition: an in-silico analysis. Journal of Biomolecular Structure and Dynamics, 1-16. doi:10.1080/07391102.2020.1796810

70. Tahmasebi, S., Saeed, B. Q., Temirgalieva, E., Yumashev, A. V., El-Esawi, M. A., Navashenaq, J. G., ... Roshangar, L. (2021). Nanocurcumin improves Treg cell responses in patients with mild and severe SARS-CoV2. Life Sciences, 276, 119437. doi:https://doi.org/10.1016/j.lfs.2021.119437

71. Toor, H. G., Banerjee, D. I., Lipsa Rath, S., \& Darji, S. A. (2021). Computational drug re-purposing targeting the spike glycoprotein of SARS-CoV-2 as an effective strategy to neutralize COVID-19. European Journal of Pharmacology, 890, 173720. doi:https://doi.org/10.1016/i.ejphar.2020.1737 $\underline{20}$

72. Umar, H. I., Josiah, S. S., Saliu, T. P., Jimoh, T. O., Ajayi, A., \& Danjuma, J. B. (2021). In-silico analysis of the inhibition of the SARS-CoV-2 main protease by some active compounds from selected African plants. Journal of Taibah University Medical Sciences, 16(2), 162-176. doi:https://doi.org/10.1016/j.jtumed.2020.12.0 $\underline{05}$

73. Vabret, A., Dina, J., Brison, E., Brouard, J., \& Freymuth, F. (2009). [Human coronaviruses]. Pathologie Biologie (Paris), 57(2), 149-160. doi:10.1016/j.patbio.2008.02.018

74. Valizadeh, H., Abdolmohammadi-vahid, S., Danshina, S., Ziya Gencer, M., Ammari, A., Sadeghi, A., . . . Ahmadi, M. (2020). Nano-curcumin therapy, a promising method in modulating inflammatory cytokines in COVID-19 patients. International Immunopharmacology, 89, 107088. doi:https://doi.org/10.1016/j.intimp.2020.1070 $\underline{88}$

75. van de Sand, L., Bormann, M., Alt, M., Schipper, L., Heilingloh, C. S., Steinmann, E., . . Krawczyk, A. (2021). Glycyrrhizin Effectively Inhibits SARSCoV-2 Replication by Inhibiting the Viral Main Protease. Viruses, 13(4). doi:10.3390/v13040609

76. Vardhan, S., \& Sahoo, S. K. (2020). In silico ADMET and molecular docking study on searching potential inhibitors from limonoids and triterpenoids for COVID-19. Computers in Biology and Medicine, 124, 103936. doi:10.1016/j.compbiomed.2020.103936

77. Vardhan, S., \& Sahoo, S. K. (2021). Virtual screening by targeting proteolytic sites of furin and TMPRSS2 to propose potential compounds obstructing the entry of SARS-CoV-2 virus into human host cells. Journal of Traditional and Complementary Medecine. doi:10.1016/j.jtcme.2021.04.001
78. Varghese, F. S., van Woudenbergh, E., Overheul, G. J., Eleveld, M. J., Kurver, L., van Heerbeek, N., . . . van Rij, R. P. (2021). Berberine and Obatoclax Inhibit SARS-Cov-2 Replication in Primary Human Nasal Epithelial Cells In Vitro. Viruses, 13(2). doi:10.3390/v13020282

79. Verma, D., Mitra, D., Paul, M., Chaudhary, P., Kamboj, A., Thatoi, H., . . D Das Mohapatra, P. K. (2021). Potential inhibitors of SARS-CoV-2 (COVID 19) proteases PLpro and Mpro/ 3CLpro: molecular docking and simulation studies of three pertinent medicinal plant natural components. Current Research in Pharmacology and Drug Discovery, 2, 100038. doi:https://doi.org/10.1016/j.crphar.2021.1000 $\underline{38}$

80. Wang, Z. Z., Li, K., Maskey, A. R., Huang, W., Toutov, A. A., Yang, N., ... Li, X. M. (2021). A small molecule compound berberine as an orally active therapeutic candidate against COVID-19 and SARS: A computational and mechanistic study. The FASEB Journal, 35(4), e21360. doi:10.1096/fj.202001792R

81. Wen, C. C., Kuo, Y. H., Jan, J. T., Liang, P. H., Wang, S. Y., Liu, H. G., ... Yang, N. S. (2007). Specific plant terpenoids and lignoids possess potent antiviral activities against severe acute respiratory syndrome coronavirus. Journal of Medicinal Chemistry, 50(17), 4087-4095. doi:10.1021/jm070295s

82. Xiong, Y., Zhu, G.-H., Wang, H.-N., Hu, Q., Chen, L.L., Guan, X.-Q., . . Ge, G.-B. (2021). Discovery of naturally occurring inhibitors against SARS-CoV2 3CLpro from Ginkgo biloba leaves via largescale screening. Fitoterapia, 152, 104909. doi:https://doi.org/10.1016/i.fitote.2021.10490 $\underline{9}$

83. Xu, J., Gao, L., Liang, H., \& Chen, S.-d. (2021). In silico screening of potential anti-COVID-19 bioactive natural constituents from food sources by molecular docking. Nutrition, 82, 111049. doi:https://doi.org/10.1016/j.nut.2020.111049

84. Yañez, O., Osorio, M. I., Areche, C., VasquezEspinal, A., Bravo, J., Sandoval-Aldana, A., . . . Tiznado, W. (2021). Theobroma cacao L. compounds: Theoretical study and molecular modeling as inhibitors of main SARS-CoV-2 protease. Biomedicine \& Pharmacotherapy, 140, 111764.

doi:https://doi.org/10.1016/j.biopha.2021.1117 64

85. Yu, S., Zhu, Y., Xu, J., Yao, G., Zhang, P., Wang, M., . . . Zhang, J. (2021). Glycyrrhizic acid exerts inhibitory activity against the spike protein of SARS-CoV-2. Phytomedicine, 85, 153364. doi:10.1016/j.phymed.2020.153364

86. Zhang, B. Y., Chen, M., Chen, X. C., Cao, K., You, Y., Qian, Y. J., \& Yu, W. K. (2021). Berberine reduces circulating inflammatory mediators in patients 
with severe COVID-19. British Journal of Surgery, 108(1), e9-e11. doi:10.1093/bjs/znaa021

87. Zhao, M., Yu, Y., Sun, L. M., Xing, J. Q., Li, T., Zhu, Y., ... Li, T. (2021). GCG inhibits SARS-CoV-2 replication by disrupting the liquid phase condensation of its nucleocapsid protein. Nature Communications, $12(1), 2114$. doi:10.1038/s41467-021-22297-8

88. Zhao, Z., Xiao, Y., Xu, L., Liu, Y., Jiang, G., Wang, W., . . Shan, H. (2021). Glycyrrhizic Acid Nanoparticles as Antiviral and Anti-inflammatory Agents for COVID-19 Treatment. ACS Applied Materials \& Interfaces, 13(18), 20995-21006. doi:10.1021/acsami.1c02755

89. Zígolo, M. A., Goytia, M. R., Poma, H. R., Rajal, V. B., \& Irazusta, V. P. (2021). Virtual screening of plant-derived compounds against SARS-CoV-2 viral proteins using computational tools. Science of The Total Environment, 781, 146400. doi:https://doi.org/10.1016/i.scitotenv.2021.14 $\underline{6400}$ 